\title{
GENETIC PARAMETERS OF LITTER GAIN TRAITS OF APRI LINE RABBITS
}

\author{
N.S. Hassan, Z.A. M. Sabra; A. S. El-Deghadi and W.A. Morsy \\ Animal Production Research Institute, Agriculture Research Center, Ministry of Agriculture, Egypt
}

\section{SUMMARY}

Litter Gain traits, (from birth till both, 21 and weaning age and from 21 days till weaning, at 35 days), for two consecutive years on APRI rabbits. The data of Litter Gain traits (LG B-21; LGB-W and $L G 21-W)$ contained a total of 192 litters produced from 80 does pedigreed by 9 sires and 12 dams, were analyzed. Heritabilities of the considered doe traits were relatively low being $0.14,0.14$ and 0.13 for Litter Gains (LG B-21; LGB-W and LG21-W); resp. Furthermore, estimates of permanent litter effects were rather low being 0.0, 0.002 and 0.002 for Litter Gain at the same manner. The ranges of the APRI does' transmitting ability $(T A \pm S E)$ for $L G_{B-21} ; L G_{B-W}$ and $L G_{21-W}$ were $(0.67 \pm 0.19,0.340 \pm 0.13$ and $0.10 \pm 0.12 \mathrm{~g}$.) with the accuracies being 0.51, 0.46 and 0.45. As for APRI dams' data transmitting ability $(T A \pm S E)$, the ranges for the same previous traits were $0.47 \pm 0.22,0.24 \pm 015$ and $0.07 \pm 0.14 \mathrm{~g}$.

Interestingly, and though of the larger numbers involved, ranges of accuracies estimates $\left(\boldsymbol{r}_{A P}\right)$ of the predicted transmitting ability (TA) were mostly higher in the dams data set followed by those of does. Furthermore, significant moderate spearman correlation estimates were obtained among various ages' $B V$ of the studied traits of data does. These estimates of correlation, however, were age dependent and decreased as age advance.

In addition, estimated epigenetic trends (EP), for Litter Gain traits under study suggested that it is possible to achieve slow, but simultaneous improvement of litter traits with selection program in rabbits. $L G$ traits recorded generally a negative EP trend during the majority of the year-seasons effects under study. As regard to EP with parities, the high $L G$ response was postponed to the $1^{\text {st }}$. parity.

\section{Keywords: rabbits, litter gain, heritability, variance components, epigenetic trend}

\section{INTRODUCTION}

Rabbits are becoming increasingly popular as an additional source of animal protein to meet the increasing demand from the ever-growing human population. Rabbit rearing has gained momentum in the recent past among the developing countries including Egypt.

Genetic improvement of Egyptian rabbits of economically important traits, particularly doe litter traits, is an important component of an expected overall strategy to improve profitability and sustainability of broiler rabbits operations. Characterization factors that affect short and long-term genetic improvement, selection, and mating strategies in a population are essential to construct and then evaluate genetic improvement programs and determine areas that need to be amended and improved.

The Egyptian animal breeds, including native rabbit ones, are supposed to be a part of our national genetic resources' wealth that must undergo more research and improvement, first to preserve them and second to reveal their distinguishing characteristic features and to promote them to compete with the exotic ones. It is therefore, the accurate determination of rabbits' genetic parameters and breeding values for most economic traits, of such populations, are essential for planning and to achieve success in their breeding plans and programs.

Post-weaning daily gains were convenient and ranged from $18-34 \mathrm{~g} /$ day in different locations studied, Youssef et al. (2008).

Thus ، the objectives of this study are, to estimate the variance components; genetic parameters and BLUP values of the Litter gain (LG) traits in APRI rabbits, and to characterize and give better understanding to the factors influencing genetic change for an economic trait yield within rabbit's population.

\section{MATERIALS AND METHODS}

APRI, maternal line rabbits (a developed line rabbits which derived from crossing of the Egyptian Baladi Red (BR) bucks with the Spanish maternal V line does) is reared in Sakha experimental rabbitery, Animal Production Research Institute (APRI), Agricultural Research Center, Ministry of Agriculture, Egypt. Field records Data of APRI line collected through two consecutive years $(2008$ - 2009) on doe litter gain traits (from birth till both 21 days and weaning and from 21 days till weaning (35 days), $\mathrm{LG}_{\mathrm{B}-21} ; \mathrm{LG}_{\mathrm{B}-\mathrm{W}}$ and $\left.\mathrm{LG}_{21-\mathrm{W}}\right)$. All rabbits were fed on the same commercial pelleted diet containing approximately $18 \%$ protein, $2.39 \%$ crude fat and 
$12.8 \%$ crude fiber. Feed and water were provided all the day long.

Breeding plan started in October 2008 and terminated at the end of spring 2009. For Breeding, each doe was transferred to the cage of its assigned buck to be bred, and palpated 10 days later. Does that failed to conceive were

\section{Statistical and genetic analysis:}

Data collected on 192 litters produced from 80 does fathered by 12 sires ( 3 of them had no information from its doe litters) and mothered by 12 dams (eight of them were bred as a does in the $1^{\text {st }}$. year and a dams in the 2.nd. one) of APRI line. Starting mixed model procedure (Co) variance matrix, for every studied age interval of the Litter gain, traits were obtained applying REML method of VARCOMP procedure of SAS, 2003, to analyzing to obtain the Least Square M. and the Proc. Means Procedure of the predicted (TA) by the Model :

$$
Y_{\text {injkm }}=U+D_{i}+S_{n}+P_{j}+M_{k}+e_{i n j k m} \cdot
$$

Where:

Yinjkm $=$ the observation on the ijklm litter; $U=$ the overall mean, common element to all observation; $\mathrm{D}_{\mathrm{i}}=\mathrm{A}$ random effect of the $\mathrm{i}$ th doe; $\mathrm{S}_{\mathrm{n}}=\mathrm{A}$ random effect of the $\mathrm{n}$ th. Sire; $\mathrm{P}_{\mathrm{j}}=\mathrm{A}$ fixed effect of the $\mathrm{j}$ th parity; $(\mathrm{j}=1,2 \ldots 4) \mathrm{M}_{\mathrm{k}}=\mathrm{A}$ fixed effect of the $\mathrm{k}$ th. year (2008 and 2009) season ( $\mathrm{k}=1$,winter; 2,Spring; 3,Summer and 4, Automn); and $\mathrm{e}_{\mathrm{injkm}}=\mathrm{A}$ random deviation of the $\mathrm{m}$ th litter and of the $\mathrm{i}^{\text {th }}$ dam.

The starting values (variance co-variance) were used for the estimation of the more precise and reliable estimates of Multi-Trait Animal Model variance and covariance components, that Data of Litter gain traits were analyzed using Derivative Free Restricted Maximum Likelihood Animal Model (DFREML) of Boldman (1995). The model adopted for analyzing the data comprised the effects of year-season combinations (as fixed effects) in addition to additive genetic and permanent environmental (as random effects, which were a combination between the doe and the parity in which the litter was born). The following animal model (in matrix notation) was used:

$$
y=X b+Z_{a} u_{a}+Z_{c} u_{c}+e
$$

Where: $y=$ vector of observations on animal for does Litter gain (LG B-21; LGB-W and LG21-W ); $b=$ vector of unknown fixed effect peculiar to year-season (5 levels); $u_{a=}$ vector of random additive genetic effects of the animal for the ith trait; $u_{c=\text { vector of random }}$ permanent environmental effect (doe - parity combination); $\mathrm{e}=$ vector of random error; $X$,
$Z_{a}$ and $Z_{c \text { are incidence matrices relating }}$ records of ith trait to the fixed, random animal and random permanent environmental effects; resp. and $\sigma 2 \mathrm{e}$ is the error variance. Standard errors of the predicted breeding values were also estimated for each individual.

The relationship coefficient inverse matrix $\left(\mathrm{A}^{-1}\right)$ among animals was as proposed by Korhonen (1996). MTDFREML program of Boldman (1995) applying the sparse matrix package, SPARSPAK was adopted for the analysis. A convergence criterion was assumed when the variance of the simplex of the loglikelihood values reached a constant value at a number of digits less than $10^{-4}$. This implies that the occurrence of local maxima was checked by repeatedly restarting the analyses until the loglikelihood values did not change beyond the first four decimal digits.

\section{Animals predicted $\left(\mathrm{TA}_{\mathrm{i}}\right)$; their accuracies $\left(\mathbf{r}_{\mathrm{AA}}\right)$, and standard errors $\mathrm{SE}_{\mathrm{Ai}}$ :}

The (co)variances matrix estimated using MTDFREML analysis is used by the same software for the prediction of (TA) values, their accuracies $\left(\mathrm{r}_{\mathrm{AA}}\right)$, and standard errors $\mathrm{SE}_{\mathrm{Ai}}$. The accuracies of BLUP for each individual was estimated according to the equation suggested by Henderson (1973), As:

$$
r_{A \hat{A}}=\sqrt{1+\mathrm{F}_{j}-\mathrm{d}_{\mathrm{j}} \alpha}
$$

Where ${ }^{r} A \hat{A}=$ the accuracy of prediction of the $i^{\text {th }}$ animal's breeding value; $F_{j}=$ inbreeding coefficient of animals (assumed equal to be zero); $\mathrm{d}_{\mathrm{j}}=$ the $\mathrm{j}^{\mathrm{th}}$ diagonal element of inverse of the appropriate block coefficient matrix; and $\alpha \mathrm{a}=$ $\sigma^{2} \mathrm{e} / \sigma^{2} \mathrm{a}$.

Standard errors of predicted breeding values $\left(s . e ._{p}\right)$ were estimated for each individual as: s.e. $p=d_{j} \sigma_{e}^{2}$; where $d_{j}$ and $\sigma_{e}^{2}$ were defined before.

\section{A: Realized association (Correlation) effect study between BLUP values and ranks:}

Another sort of genetic correlation that differs from that resulted from multi-trait animal model analysis in that the former expresses realized association between animal's breeding values while the later expresses estimated expected additive genetic association between loci involved in the inheritance of the two traits under consideration (either temporary due to that these loci are carried on the same chromosomes or permanent due to that some of these loci may have control on both traits). However, the later is very sensitive to the number of traits involved in 
the animal model analysis and the value between a particular two traits diminishes drastically as the number of traits analyzed increases.

The transmitting abilities (BLUP) estimated by MTDFREML as well as their estimated ranks are used to estimate the Product moment, (for BLUP's), and Spearman, (for BLUP ranks), realized association (correlation) coefficients among the studied litter traits for entire group of animals; sires; dams and does were done.

\section{B: Epigenetic Trend:}

Genetic improvement of rabbits for economically important traits, particularly litter traits, is an important component of an overall strategy to improve profitability and sustainability of rabbits. Factors that influence genetic improvement may vary across environmental situations. Differences among such situations (e.g. parity, Month or season of kindling, etc...) were found to be important on farm litter traits' performance (Hassan et al., 2010 and 2013). The cumulative effects of such genes, coupled with environmental effects produce continuous variation in the phenotypic values of individual. The differences among classes of distinctive environmental situations may affect litter traits genetic improvement within rabbit populations, and will help identify common factors that influence genetic improvement across populations in Egyptian rabbit populations.

Epigenetic trend (as a sort of genetic by environment interaction) were estimated using the method reported by Legates and Myers (1988). After regressing the BLUP values of the engaged animals across the different classes of the insinuated environmental situations using SAS merge statement (SAS, 2003), epigenetic trends are typically calculated as the deviation of the mean of the (TA's) of the particular group of animals succeeded to re-produce under the environmental situations they were subjected to, from the overall mean of entire group of animals' across all environmental situations' BVs. The resultant output was then plotted in graphs to represent the general trend of the behavior of a specific trait under changeable classes of the fixed effect under consideration (i.e. year season, YRS and parity, P).

\section{C: Environmental Trend (ENV):}

Environmental Trends are estimated as the result of subtracting TA's of LG values of an animal from its observed phenotypic values of the same traits, all as deviations from the overall means of the whole tested rabbit population environmental divergences. The resultant Litter gain (ENV_LG) values are regressed matching their respective year-season combinations (YRS) and parity effects $(\mathrm{P})$ as done with the epigenetic trends. Thereafter, they evaluated by the same way done with epigenetic trends.

\section{RESULTS AND DISCUSSION}

Means and coefficients of variation of uncorrected records, and Least Square means:

Overall actual means of LG traits in APRI rabbits, standard deviations and coefficients of variation $(\mathrm{CV} \%)$ during the suckling period are presented in table (1). Means of Litter gain traits ( $\mathrm{LG}_{\mathrm{B}-21} ; \mathrm{LG}_{\mathrm{B}-\mathrm{W}}$ and $\mathrm{LG}_{21-\mathrm{W}}$ ) in this study were within the ranges reviewed in most of the Egyptian studies (Azoz and El Kholy, 2006 on Bauscat rabbits, Kishk et al., 2006). Coefficients of variability for Litter gain (CV \%) ranged from 37.80 to $50.64 \%$. The eminent data variability may reveal that new APRI line rabbits have a relatively substantial variability and it could possibly constitute a rich genetic resource to work upon. In the study on Baladi Black rabbits done by Abdel-Kafy et al. (2012), they reported that such native breed of rabbits with its high performance is ready to be given more attention for genetic improvement.

\section{Parity and Year-season combination effect:}

Parity (Table 2) had no effect on all Litter gain traits, while year-season combinations (YS) showed significant effects on LGB-W and LG21$\mathrm{W}$ traits. That there is a trend of LG figures due to YS; which is more obvious in these intervals (LGB-W and LG21-W) ) that litters of winter kindlers gained significantly more followed generally by autumn kindlers.

\section{Variance component estimates $\left(\sigma^{2}\right)$ :}

An inconsistent trend was observed in APRI rabbits, for $L G$ additive genetic variance $\left(\boldsymbol{\sigma}_{\mathrm{A}}^{2}\right.$; diagonal elements) as values and to some extent as proportion of the total observed variance (Table 3).

Though $\mathrm{LG}_{\mathrm{B}-\mathrm{W}}$ and $\mathrm{LG}_{21-\mathrm{W}}$, seemed generally to be age dependent with their ratios decreased as compared to $\mathrm{LG}_{\mathrm{B}-21}$. However; litter traits as fitness and transitional traits are expected to be marginal with consumed additive genetic variance due to that they are being continually subject to natural selection. In this respect, the phenotypic variance which is very high, (diagonal elements) of Litter gain traits, as expected and know, followed the same curvilinear age dependent trend like that of $\boldsymbol{\sigma}_{\mathrm{A}}{ }_{\mathrm{A}}$, nonetheless being the highest gain early in life and decreased thereafter (Table 3), reflecting the enormous environmental component of variance associated with the doe during the suckling period and raising of its litters to weaning.

Permanent environmental effects of LG traits were found to be negligible and very low in its magnitude. Conversely, Youssef et al. (2003) 
reported that Litter weight traits are greatly affected by the additive genetic and maternal effects. In this respect, Khalil et al. (1987) reported that the low percentages of sire variance component reflect the large environmental component of variance associated with the doe during kindling and raising of its litters to weaning. He also added that since milk production traits are of the fitness traits and are influenced by Litter gain, it is supposed that the additive variance has been diminished through long term natural selection.

Table 1. Overall Means, standard deviations (SD) and coefficients of variability (CV \%) of Litter gain ( $\mathrm{LG}_{\mathrm{B}-21} ; \mathrm{LG}_{\mathrm{B}-\mathrm{W}}$ and $\mathrm{LG}_{21-\mathrm{W}}$ ) traits for the APRI rabbits line

\begin{tabular}{lccc}
\hline Trait & Overall Mean & SD & CV \\
\hline $\mathrm{LG}_{\text {B-21 }}$ (g.) & 0.054 & 0.020 & 37.800 \\
$\mathrm{LG}_{\mathrm{B}_{-} \mathrm{W}}$ (g.) & 0.076 & 0.299 & 39.200 \\
$\mathrm{LG}_{21 \_ \text {w }}$ (g.) & 0.170 & 0.086 & 50.640 \\
\hline
\end{tabular}

Table 2. Least Square Mean ( \pm SE) of Litter gains $\left(\mathbf{L G}_{\mathrm{B}-21} ; \mathbf{L G}_{\mathrm{B}-\mathrm{W}}\right.$ and $\left.\mathbf{L G}_{21-W}\right)$ for the APRI line

\begin{tabular}{|c|c|c|c|c|c|c|c|}
\hline & \multirow{2}{*}{ No. } & \multicolumn{2}{|c|}{$\mathrm{LG}_{\mathrm{B}-21}$} & \multicolumn{2}{|c|}{$\mathrm{LG}_{\mathrm{B}-\mathrm{W}}$} & \multicolumn{2}{|c|}{$\mathrm{LG}_{21-\mathrm{W}}$} \\
\hline & & LS-Mean \pm & $\mathrm{SE}$ & LS-Mean \pm & SE & LS-Mean \pm & SE \\
\hline $\begin{array}{l}\text { Overall Mean } \\
\text { (MU) }\end{array}$ & 192 & 0.050 & 0.003 & 0.070 & 0.004 & 0.154 & 0.010 \\
\hline Parity & & \multicolumn{2}{|c|}{ Not Sig. } & \multicolumn{2}{|c|}{ Not Sig. } & \multicolumn{2}{|c|}{ Not Sig. } \\
\hline $1^{\text {st }}$ & 85 & 0.052 & 0.004 & 0.069 & 0.005 & 0.145 & 0.013 \\
\hline $2^{\text {nd }}$ & 44 & 0.050 & 0.005 & 0.072 & 0.006 & 0.163 & 0.017 \\
\hline $3^{\text {rd }}$ & 32 & 0.050 & 0.005 & 0.070 & 0.008 & 0.151 & 0.020 \\
\hline $4^{\text {th }}$ & 31 & 0.047 & 0.006 & 0.068 & 0.008 & 0.157 & 0.021 \\
\hline Year-Season & & \multicolumn{2}{|c|}{ Not Sig. } & \multicolumn{2}{|c|}{ Sig. } & \multicolumn{2}{|c|}{ Sig. } \\
\hline 83 & 20 & 0.044 & 0.007 & $0.059^{\mathrm{b}}$ & 0.010 & $0.131^{\mathrm{c}}$ & 0.025 \\
\hline 84 & 33 & 0.051 & 0.005 & $0.073^{\mathrm{a}}$ & 0.008 & $0.162^{\mathrm{b}}$ & 0.020 \\
\hline 91 & 31 & 0.058 & 0.005 & $0.086^{\mathrm{a}}$ & 0.007 & $0.197^{\mathrm{a}}$ & 0.019 \\
\hline 92 & 108 & 0.045 & 0.003 & $0.060^{\mathrm{b}}$ & 0.004 & $0.126^{\mathrm{c}}$ & 0.011 \\
\hline
\end{tabular}

Table 3. Additive genetic $\left(\sigma_{A}^{2}\right)$ and phenotypic co-variance, $\%$ of permanent environment as proportion of the phenotypic variance of Litter gains $\left(\mathbf{L G}_{\mathrm{B}-21} ; \mathbf{L G}_{\mathrm{B}-\mathrm{W}}\right.$ and $\left.\mathbf{L G}_{\mathbf{2 1}-\mathrm{W}}\right)$

\begin{tabular}{|c|c|c|c|c|c|c|c|c|c|}
\hline & \multicolumn{3}{|c|}{ Additive genetic $\left(\sigma_{A}^{2}\right)$ variance } & \multicolumn{3}{|c|}{ Phenotypic Variances And Covariances } & \multicolumn{3}{|c|}{ \% Uncorrelated Random Effects } \\
\hline & $\mathbf{L G}_{\mathrm{B}-21}$ & $\mathbf{L G}_{\mathrm{B}-\mathrm{W}}$ & $\mathbf{L G}_{21-W}$ & $\mathbf{L G}_{\mathrm{B}-21}$ & $\mathbf{L G}_{\mathbf{B \_ W}}$ & $\mathbf{L G}_{21 \_W}$ & $\mathbf{L G}_{\mathrm{B}-21}$ & $\mathbf{L G}_{\mathbf{B \_ W}}$ & $\mathbf{L G}_{21} \mathrm{~W}$ \\
\hline $\mathbf{L G}_{\mathrm{B}-21}$ & $\frac{\mathbf{0 . 1 7 5}}{0.134}$ & 0.117 & 0.064 & $\underline{1.273}$ & 0.832 & 0.549 & $\underline{0.000}$ & & \\
\hline $\mathbf{L G}_{\mathbf{B}_{-} \mathbf{W}}$ & 0.117 & $\frac{\mathbf{0 . 1 5 1}}{0.135}$ & 0.141 & 0.832 & $\underline{1.111}$ & 1.106 & 0.940 & $\underline{0.002}$ & \\
\hline $\mathbf{L G}_{21 \_W}$ & 0.064 & 0.141 & $\underline{\mathbf{0 . 1 5 6}}$ & 0.549 & 1.106 & $\underline{1.227}$ & 0.840 & 0.970 & $\underline{0.004}$ \\
\hline
\end{tabular}

Table 4. Heritabilities and genetic correlations, environment (error as proportion of the total phenotypic variance) of Litter gains ( $\mathrm{LG}_{\mathrm{B}-21} ; \mathbf{L G}_{\mathrm{B}-\mathrm{W}}$ and $\mathbf{L G}_{21-W}$ ) for APRI rabbits

\begin{tabular}{|c|c|c|c|c|c|c|c|}
\hline \multicolumn{4}{|c|}{ Heritabilities and genetic correlations } & \multicolumn{4}{|c|}{ Error Co-variance as a proportion of total variance } \\
\hline & $\mathbf{L G}_{\text {B-21 }}$ & $\mathbf{L G}_{\mathbf{B} \_\mathbf{W}}$ & $\mathbf{L G}_{21 \_W}$ & & $\mathbf{L G}_{\mathrm{B}-21}$ & $\mathbf{L G}_{\mathbf{B} \_W}$ & $\mathbf{L G}_{21 \_w}$ \\
\hline $\mathbf{L G}_{\mathrm{B}-21}$ & $\underline{0.140}$ & & & $\mathbf{L G}_{\mathrm{B}-21}$ & $\underline{\mathbf{0 . 8 6 0}}$ & & \\
\hline $\mathbf{L G}_{\mathbf{B}_{-} \mathbf{W}}$ & 0.720 & $\underline{\mathbf{0 . 1 4 0}}$ & & $\mathbf{L G}_{\mathbf{B}_{-} \mathbf{W}}$ & $\overline{0.700}$ & $\underline{0.860}$ & \\
\hline $\mathbf{L G}_{21} \mathbf{W}$ & 0.390 & $\overline{0.920}$ & $\underline{0.130}$ & $\mathbf{L G}_{21} \mathbf{W}$ & 0.450 & $\overline{0.950}$ & $\underline{0.870}$ \\
\hline
\end{tabular}

\section{Heritability estimates:}

Heritability estimates for LG traits in APRI rabbits, were relatively low, from $0.13-0.14$, (table 4). These estimates were comparable with those ranges reported by El-Raffa (2000), and Nofal et al. (2002). These low $h^{2}$ figures may be attributed to the consumption of the additive genetic variance due to natural selection which consequently led to inflated non additive genetic and environmental factors. In this respect, Khalil (1987) concluded that environmental conditions and non-additive genetic effects play a large role in doe litter traits in rabbits. Therefore, such diminished estimates for heritability for these traits may reveal higher non additive 
genetic effects for all studied litter traits. Marker assisted selection would be the preferred technique. Indirect selection for litter traits from its component traits as a consequence of their nature as composite traits could be an alternative solution key especially in the positively high correlated traits. However, using actual transmitting ability of animals from reliable models of estimation would enhance more the genetic response.

\section{Genetic correlation:}

All estimates of genetic correlations among Litter gains (Table 4) were high and positive, except for the association between LG B-21 and LG21_W (0.39), this low estimate may be due to the independency relationship between these traits. Thus we may build the strategy of the selection criteria on the high correlated traits.

\section{Animal Evaluation: \\ Transmitting abilities (TA's); Accuracies $\left(r_{A A}\right)$ and Standard error (SE):}

Estimates of APRI rabbits transmitting abilities (Statistically BLUP's), their accuracies $\left(\boldsymbol{r}_{\boldsymbol{A A}}\right)$ and Standard errors (SE) for Litter gain traits are presented in table (5). From results presented in table (5), it is obvious that the minimum and maximum values as well as difference between them (ranges) of TA and the number of positive records are age dependent and they decreased as the period post kindling lengthened till weaning at $5 \mathrm{wks}$ of age. Fortunately, the percentage number of positive records $(\mathrm{n}+)$ for the whole, does' and dams' data didn't get behind or set down the border of $25 \%$ (which is the maximum expected number of replacement females). However and as for sires, the situation is differed since they were at the border of (2 sires) $22 \%$. The trend consistency of positive records may reveal that there may be a positive association between the traits on the animals of positive records, which will be dealt with in the part of association studies between BLUP's of Litter gain traits. The later conclusion, if true will help the breeders of these line rabbits to make their decision of selecting early in bunnies life based on the birth BLUP values.

This would reduce the generation intervals and cuts down the breeding costs. Nevertheless, the SE values are relatively high at early ages which may impose difficulty of making such a decision of early selection but fortunately again the reliability or accuracies $\left(\boldsymbol{r}_{A A}\right)$ of the higher records are outstandingly high.
In this respect the higher the $\boldsymbol{r}_{\boldsymbol{A} \boldsymbol{A}}$ values, the more reliable is the BLUP's and the more certain the breeder is about the results of the selection decision. Generation interval is the average age of a sire or dam when a potential replacement progeny is born. However, sires TA estimates are superior when compare with does and dams' data. This could be advantageous yet again, since sires constitute almost $50 \%$ of the hereditary of the next generation of animal. The later presumption coupled with an elevated selection intensity pressure of the sires may reveal that the additive genetic makeup of the next generation of this line rabbit population is expected to be larger than that would think of based on dams', does' or whole population data (i.e.is expected to yield a greater LG traits selection response). In this respect, El-Raffa et al. (1997) reported that differences between minimum and maximum values of the top $25 \%$ sire breeding value estimates are the backbone for any planned selection strategy to improve economic traits.

\section{Realized genetic correlation estimates among breeding values and its Rank correlations:}

Correlation studies (Product Moment for BLUP values and Spearman for BLUP ranks) among the breeding values of LG traits Estimates for all; does', dams' and sires' data are presented in table (6).

However, data of table (6) revealed that the ranges of bivariate Product Moment or Spearman association coefficients among LG traits in the all data were generally moderate, and negative in direction. It, either Spearman between LG BLUP ranks or Pearson between LG BLUP values, were generally negative in direction and weak between $\mathrm{LG}_{\mathrm{B}-21} ; \mathrm{LG}_{\mathrm{B}-\mathrm{w}}$, Intermediate between $\mathrm{LG}_{\mathrm{B}-\mathrm{w}}$ and $\mathrm{LG}_{21-\mathrm{W}}$ while it is strong between $\mathrm{LG}_{\mathrm{B}-21} ; \mathrm{LG}_{21-\mathrm{W}}$.

However, the first two types of correlation are Overlapping or Intersecting coefficient and somehow they constitute part-of-all correlation type. However, the third correlation (i.e. between $\mathrm{LG}_{\mathrm{B}-21}$; $\left.\mathrm{LG}_{21-\mathrm{W}}\right)$ is easier to understand and interpret. This may reveal that if $L G$ is weak in some era of the studied period, there would be a compensatory or balance growth in the remnants or the reciprocal era. The reason for such a phenomena is perhaps, because there is a boundary or a margin for a breed of rabbit as regard to the total gain during the suckling period. If such an assumption is true, the results reflects that we can accelerate the gain per litter at part of the period and not in the whole period and the selected acceleration period would be advantageously chosen on economic or biological basis. 
Table 5. Ranges of transmitting abilities (TA); Standard Errors $\left(\mathrm{SE}_{\mathrm{Ai}}\right)$ and Accuracies $\left(r_{A A}\right)$ in addition to positive records (+) of Litter gains ( $\mathbf{L G}_{\mathrm{B}-21} ; \mathbf{L G}_{\mathrm{B}-\mathrm{W}}$ and $\left.\mathbf{L G}_{21-\mathrm{W}}\right)$ for APRI rabbits

\begin{tabular}{|c|c|c|c|c|c|c|c|c|c|c|c|c|c|}
\hline & & \multicolumn{3}{|c|}{ All Data } & \multicolumn{3}{|c|}{ Does Data } & \multicolumn{3}{|c|}{ Dams Data } & \multicolumn{3}{|c|}{ Sires Data } \\
\hline & & 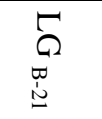 & $\overbrace{\substack{1 \\
\Sigma}}^{1}$ & $\underset{\frac{1}{3}}{5}$ & $\overbrace{\substack{0\\
}}$ & $\overbrace{\substack{1 \\
\Sigma}}^{5}$ & $\overbrace{\substack{1 \\
\Sigma}}^{5}$ & 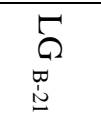 & 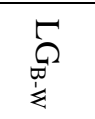 & $\& \underset{\widetilde{N}}{\underline{N}}$ & 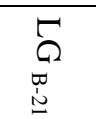 & $\overbrace{\substack{\infty \\
\Sigma}}$ & 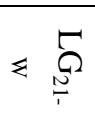 \\
\hline No. & & & 91 & & & 80 & & & 12 & & & 9 & \\
\hline & TA & 0.69 & 0.34 & 0.10 & 0.67 & 0.34 & 0.10 & 0.47 & 0.24 & 0.07 & 0.43 & 0.21 & 0.05 \\
\hline & SE & 0.22 & 0.15 & 0.14 & 0.19 & 0.13 & 0.12 & 0.22 & 0.15 & 0.14 & 0.14 & 0.11 & 0.10 \\
\hline & $r_{A A}$ & 0.88 & 0.79 & 0.75 & 0.51 & 0.46 & 0.45 & 0.88 & 0.79 & 0.75 & 0.48 & 0.49 & 0.50 \\
\hline \multicolumn{14}{|c|}{ Positive Records } \\
\hline Number & & 62 & 62 & 61 & 54 & 54 & 53 & 5 & 5 & 5 & 6 & 6 & 6 \\
\hline$\%$ & & 68.13 & 68.13 & 67.03 & 67.50 & 67.50 & 66.25 & 41.67 & 41.67 & 41.67 & 66.67 & 66.67 & 66.67 \\
\hline & Min & 0.18 & 0.09 & 0.02 & 0.17 & 0.09 & 0.02 & 0.19 & 0.09 & 0.02 & 0.06 & 0.04 & 0.02 \\
\hline & Range & 0.16 & 0.08 & 0.03 & 0.15 & 0.08 & 0.03 & 0.12 & 0.06 & 0.01 & 0.28 & 0.13 & 0.03 \\
\hline SE & & 0.11 & 0.06 & 0.05 & 0.09 & 0.04 & 0.03 & 0.17 & 0.10 & 0.08 & 0.00 & 0.00 & 0.00 \\
\hline$r_{A A}$ & & 0.07 & 0.10 & 0.14 & 0.06 & 0.10 & 0.13 & 0.01 & 0.04 & 0.05 & 0.05 & 0.08 & 0.08 \\
\hline
\end{tabular}

Table 6. Realized genetic Correlation Coefficients (above Diagonal: Product Moment between BLUP values; below Diagonal: Spearman between BLUP ranks) of Litter gains ( $\mathbf{L G}_{\text {B-21 }}$; $\mathbf{L G}_{\mathrm{B}-\mathrm{W}}$ and $\mathrm{LG}_{21-W}$ ) for all, does', dams' and sires' data of APRI Rabbits

\begin{tabular}{|c|c|c|c|c|c|c|c|}
\hline All Data & LGB-21 & LGB-W & LG21-W & DoesData & LGB-21 & LGB-W & $\mathbf{L G}_{21-W}$ \\
\hline LGB-21 & 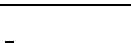 & -0.241 & -0.69 & LG B-21 & & -0.101 & -0.749 \\
\hline$\overline{\text { LGB-W }}$ & -0.166 & & $-\overline{-0.536}$ & LGB-W & -0.104 & & -0.583 \\
\hline$\overline{\mathrm{LG} 21-\mathrm{W}}$ & -0.635 & -0.606 & & $\overline{\mathrm{LG} 21-\mathrm{W}}$ & -0.687 & -0.591 & - \\
\hline \multicolumn{8}{|c|}{$\mathrm{N}=20 \overline{3}$} \\
\hline Sires Data & LGB21 & LGBW & LG21W & DamsData & $\underline{\text { LGB21 }}$ & LGBW & $\underline{\mathrm{LG}} 21 \mathrm{~W}$ \\
\hline LGB21 & - & 0.283 & -0.854 & LSB & & -0.762 & -0.442 \\
\hline$\overline{\mathrm{LGBW}}$ & $\underline{0.117}$ & & -0.741 & $\overline{\mathrm{LS} 21}$ & -0.184 & & $\overline{-0.244}$ \\
\hline$\underline{\mathrm{LG}} 21 \mathrm{~W}$ & $\underline{-0.75}$ & $\underline{-0.583}$ & & $\underline{\mathrm{LSW}}$ & -0.632 & -0.558 & - \\
\hline \multicolumn{8}{|c|}{$\mathrm{N}=9$} \\
\hline
\end{tabular}

Epigenetic Trend

Epigenetic Trend (EGT):

Epigenetic trends which are estimated as a deviation from the overall BLUP values' mean of the whole tested rabbit population for Litter gain (EPG_LG) traits as affected by parity (P) and yearseason combinations (YS) were illustrated in figures (1 and 2). Results shown in figure (1), that all LG traits' genetic change with Parity effects gave generally equivalent and comparable patterns (the first parity of all ages gave positive $(+)$ trends while the remainder parities gave negative trends), which may generally reveals analogous related (genotype X environment) interaction in APRI rabbits parities.

The high APRI litter gain epigenetic trend at the first parity is apparently due to substantial compatibility between physiological, and reproductive maturity development. Rabbit better performance is reached at these specific parities with slight differences between rabbit breeds (Hassan et al., 2010 and Hassan et al., 2013).

Results in figure (2), revealed that all LG traits' genetic change with Year-season (YRS) effects gave a comparable and positive trend (YRS 93 and YRS 92) (2nd Year-Summer and Spring) that gave a stepby-step progressive positive trends while all the rest gave approximately no or negative trends).
The expected explanation for the former situation which may characterize with high performance and prolificacy of the bunnies that exploit their adapted acquired performance to express themselves in Summer (hot months) or may be the performance conformity with the high loss of bunnies due to hot stress in these months. The negative (low) LG epigenetic trend during autumn and winter of the first year, 2008 evidently comprehensible as the animals are not exploiting their performance may be exposed to factors that affect their prolificacy, specially feeding and slight infections around the low year temperature. Fatmah 2014 revealed that epigenetic trends for post weaning body weights regressed against parity at all ages under her thesis study were near zero. She added that, this could be due to that there were only three parity classes or that postweaning growth traits is inconsiderably affected by parity because the maternal effect at these ages would be weak. 


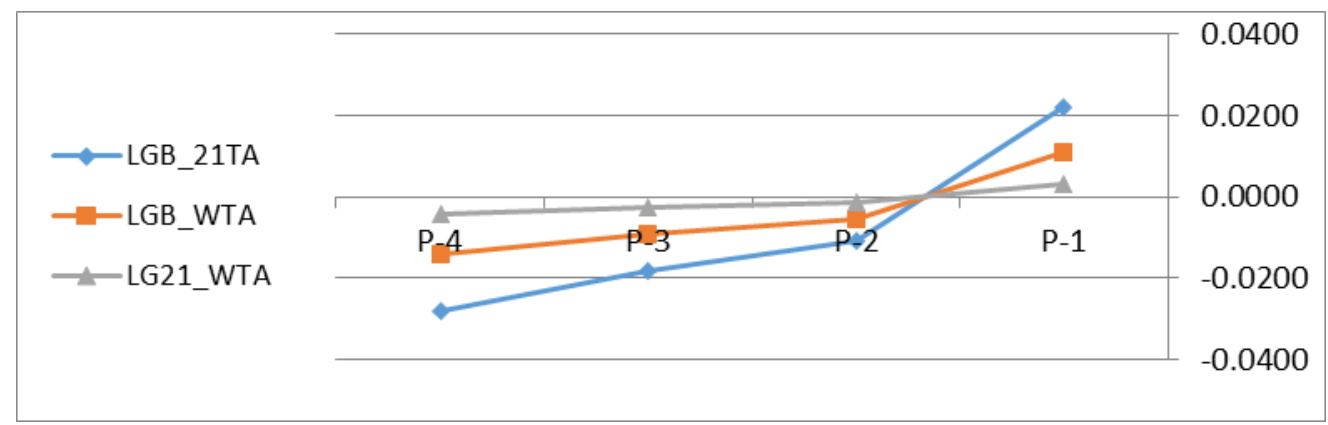

Fig 1. Epigenetic trend of BLUP values of LG traits regressed against parity

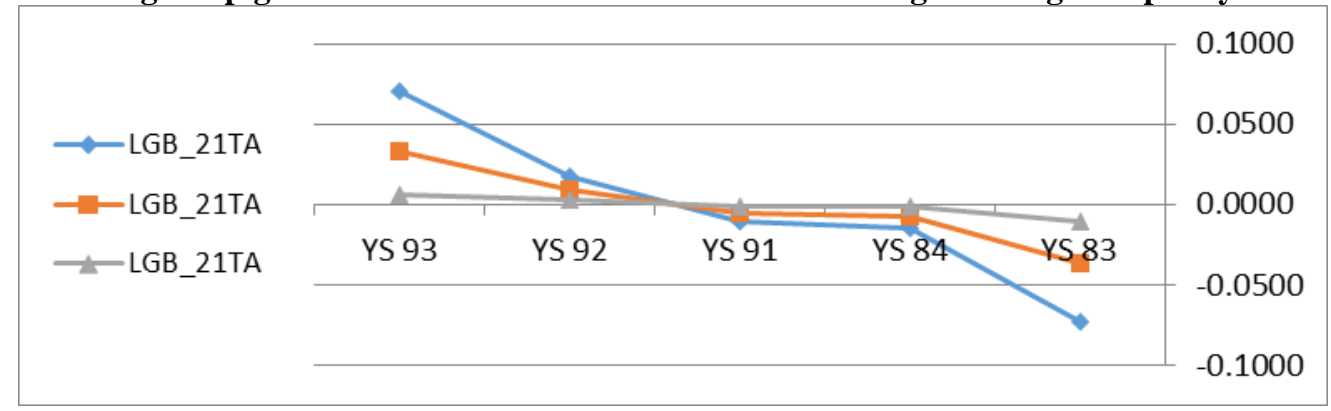

Fig 2. Epigenetic trend of BLUP values of LG traits regressed against Year-season

\section{Environmental Trend (Env LG):}

Litter gain (Env_LG) traits as affected by Yearseason and parity were illustrated in figures ( 3 and 4 ). The two graphs revealed that Litter gains of the tested rabbit population have an obvious trend that the changes due to both parity and year-season are the same in general. Nevertheless, across evaluated ages as the litters becomes older the changes seems to get more profound and radical making it obvious to divide the pre-weaning period as to the sensitivity to environmental situations into early and late preweaning periods. While at the early pre-weaning period the suckling mothers play a role in smoothing the sensitivity to the difference in environments, the later pre-weaning period the individual capability of the bunnies (may be have an adaptation response) appears as more reflection to environmental situations.

As regard to Litter gains environmental changing by Year-season combinations, showed that Litter gain traits have a negative environmental trend during the second and third season (spring and summer) of the second year, meaning that the effects of environment was favorable against animals during these months. The high LG performance of the tested population versus environment trends are evidently comprehensible as the animals are in these periods, exploiting the favorable proximate conditions and also the favorable abundant fodder diets like alphalpha.

However, such detected adverse or undesirable environmental effect during autumn and winter (positive environmental effect) may be due to the lack of green fodders.

As for environment $\mathrm{X}$ parity interaction, data of environment trends presented in figure (3), revealed that the effects of environment was negative for LG in the $1^{\text {st }}$ parity, that animals are in their first production and having its adequate rearing , otherwise, it started to have a positive trends especially in the $2^{\text {nd }}$ and $3^{\text {rd }}$ ones. This Positive environment trend seems to concentrate in the $2^{\text {nd }}$ and $3^{\text {rd }}$ parities, seemingly because does may have an inadequate rearing and managerial conditions.

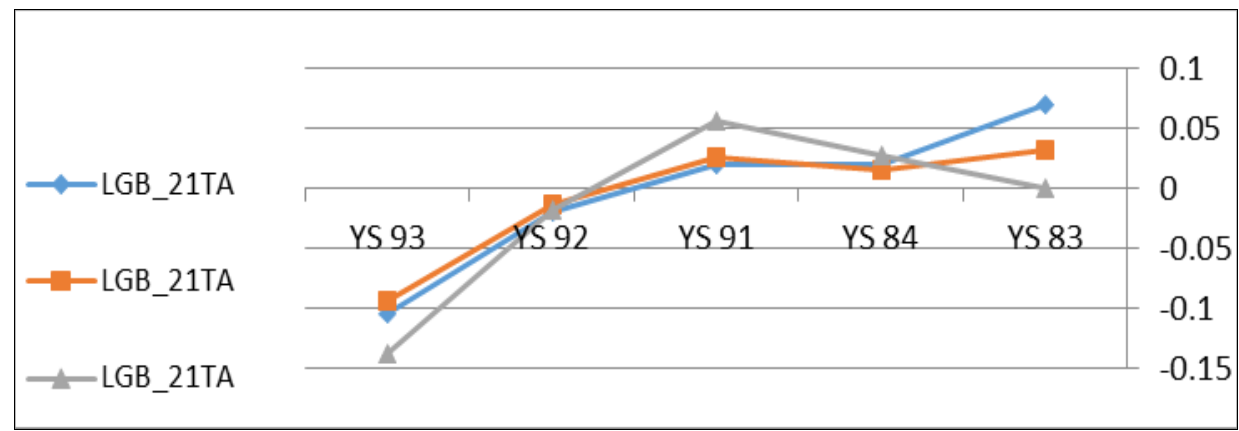

Fig 4. LG traits environmental values trend as regressed against Year-season 


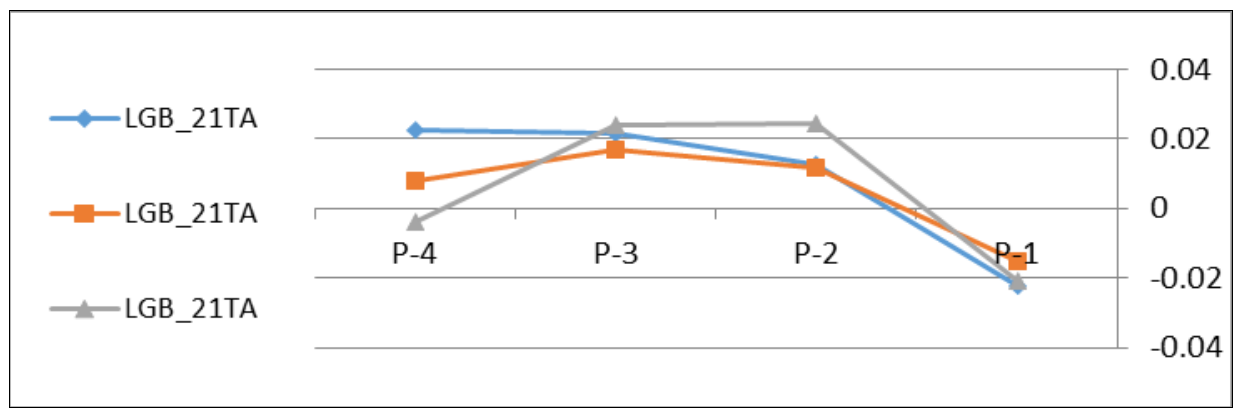

Fig 3. LG traits environmental values trend as regressed against Parity

\section{CONCLUSION}

Heritabilities of LG traits seemed to be too weak to be used through individual selection. Therefore, family or within family selection would be a solution or preferably crossing with other lines or back cross with its favorable parents.

The positive association between the traits on the animals of positive records will be dealt with the positive association between BLUP's of Litter gain traits, which selection can be done on the highest breeding value traits.

As a clarification of the whole idea about the epigenetic changes in response to the environmental situations, it seems that when the environmental situations are harsh, the first priority of the animal's biological system is to maintain its life at the expense of production (low epigenetic trend). Likewise, when the situations are optimum, it is the time for the biological system to express its whole genetic capabilities expressed as epigenetic trend.

This line rabbits with its high performance is ready to be given more attention for genetic improvement through selection (especially with the large additive component of variance at weaning) and crossbreeding with sensibly and conscientiously chosen standard breeds to produce resourceful broiler rabbits especially with the large components of non-additive genetic component of the studied Litter gain traits. However, backcrossing with the founder breeds either the locale to improve quite a bit the acclimatization to the environment or to the standard to increase the adaptation to the hot weather environment and percentage of blood contribution and in both cases to stabilize the performance against segregation.

\section{REFERENCES}

Abdel-Kafy E.M, Hassan N.S., Morsy W.A., Ali Kh.A.A., El-Sawy M.A., Hassanein M.N.F., Sabra Z.A.M., 2012. Genetic parameters of litter traits in a local Baladi black rabbit in Egypt. 10th World Rabbit Congress - September 3 - 6, 2012Sharm El-Sheikh -Egypt, 37-41.

Azoz A.A. and K.H. El-Kholy, 2006. Reproductive performance and blood constituents of V-line and Bauscat Female rabbits under middle Egypt conditions. Egyptian J. of rabbit science, 16 (1): 139-160.
Boldman, K. G., L. A. Kriese, L. D. Van Vleck, C. P.Van Tassell and Kachman S. D., 1995. A Manual for Use of MTDFREML. A Set of Programs to Obtain Estimates of Variances and Covariances [DRAFT]. U.S. department of Agriculture, Agricultural Research Service, USA.

El-Raffa A. M., M. K. Shebl, M.A. Kosba and M.H. Khalil, 1997. Sire and Dam transmitting abilities for litter size traits in three lines of rabbits raised in high intensive system of production. Egyptian J. of rabbit science, 7 (2): 67-79.

El-Raffa, A. M., 2000. Animal Model Evaluation of V Line Rabbits Raised Under Egyptian Condition. Egyption Journal of Rabbit Science, 10 (I): 75 82.

Fatmah M. A B., 2014.Genetic Study for Some Body Measurements and Its Relationship with Some Productive Traits in Rabbits. Ph.D. Thesis, Faculty of Agriculture, Tanta University, Egypt.

Hassan N. S.; Abdel-Ghany A. M.; Hanan H. Ghanem; M. A. El-Shennawy and Mona M. Ghaly , 2013. Genetic evaluation of the native Baladi Black rabbits under North Deltaweather of Egypt using Animal Model procedure. A: Doe litter traits. Journal of Animal, Poultry \& Fish Production, Suez Canal University, Vol (1), 2013: 13-22.

Hassan, N. S.; Farid, A.; Abdel-Ghany, A. M.; Sabri, H. M.; Ahmed, E. G.; and Mona M. Ghaly , 2010: Epigenetic Trend of Milk Yield and Litter Gain Traits in Californian Rabbits. The 6thInternational Conference on Rabbit Production in $\mathrm{Hot}$ Climates, 1-4 Feb. Assiut., Egypt.

Henderson, C. R.,1973. Sire Evaluation and Genetic Trends. In: Proc. Anita. and Genet. Symp. In Honor of J. L. Lush. pp 10: 41. Amer. Soe. Anim. Sci., Champaign, IL.

Kishk W.H., Khalil H.A., Hassanein A.M. and M.A. Ayoub, 2006. Physiological, Reproductive and Productive traits of New Zealand White rabbit does as affected by natural mating time. Egyptian J. of rabbit science, 16 (2): 223-232.

Khalil, M.H., Owen, J.B. and E.A. Afifi, 1987. A genetic analysis of litter traits in Bauscat and Giza White rabbits. Anim. Prod., 45: 123:134.

Legates, J. E. and R. M. Myer, 1988: Measuring Genetic Change in a Dairy Herd Using a Control Population. J. Dairy Sci., 71(4):1025- 1033. 
Nofal, R.Y., A. M. Abdel-Ghany and K. Saleh, 2002. Best Linear Unbiased Prediction (BLUP) on Some Litter Traits and Masculinity Rate of New Zealand White Rabbits Under Egyptian Conditions. The $3{ }^{\text {rd }}$ Scientific Conference on Rabbit Production in Hot Climates, Hurghada, Egypt 8-11 October, 127-137.

SAS., 2003. SAS OnlineDoc 9.1.3. SAS Institute Inc., Cary, NC, USA.
Searle, S. R., 1989. Variance Component Some History and a Summary Account of Estimation Methods. Anim. Breed. Genetics. 106: 129

Youssef Y.M.K., M.M. Iraqi, A.M. El-Raffa, E.A. Afifi, M.H. Khalil, M.L. García and M. Baselga, 2008. A joint project to synthesize new lines of rabbits in Egypt and Saudi Arabia: emphasis for results and prospects. The $9^{\text {th }}$ World Rabbit Congress, 10-13 June, 2008.Verona, Italy. 16371642 .

المقاييس الوراثية لصفات معدلآت النمو لخلفة الأرانب الأبرى

ناجى سعيد حسن، زين العابدين عبد الحميد محمد صبره، أميرة سليمان عبد الحميد الدغيدي، وائل عوض محمود مرسي

معه بحوث الإتتاج الحبيوانس، مركز البحوث الزراعية، وزارة الزراعة، الجبزة-الدقى، مصر

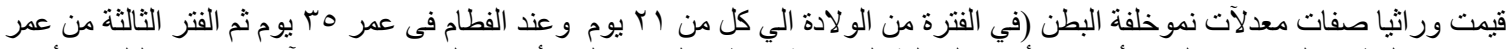

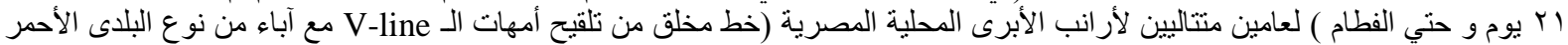

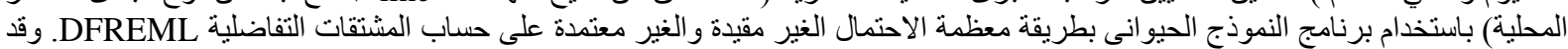

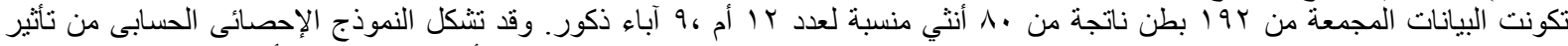

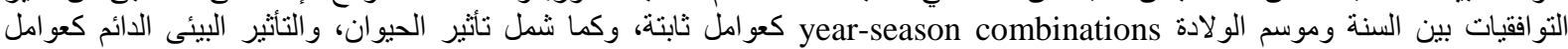

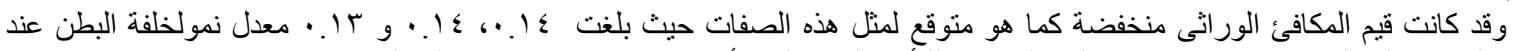
عشوائية

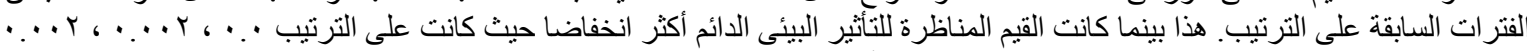

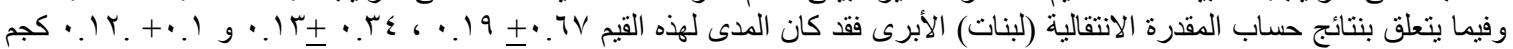

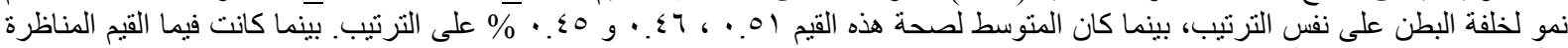

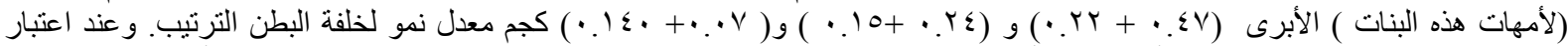

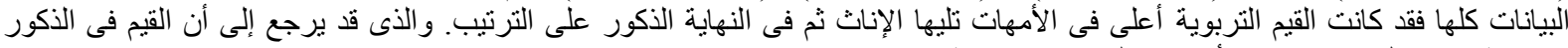

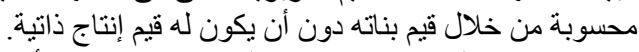

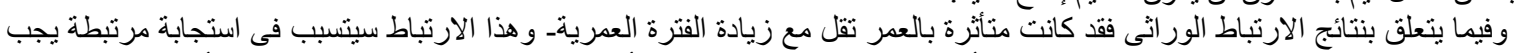

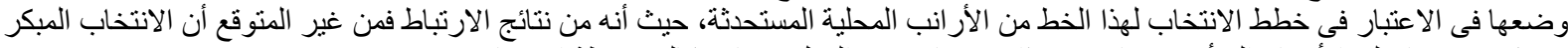

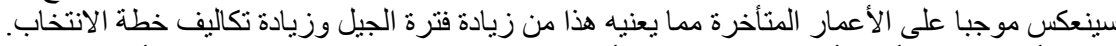

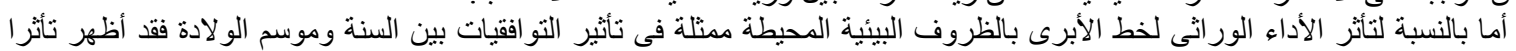

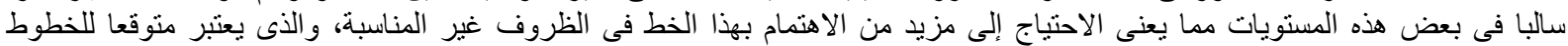

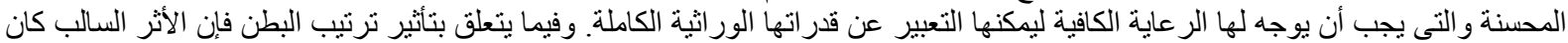

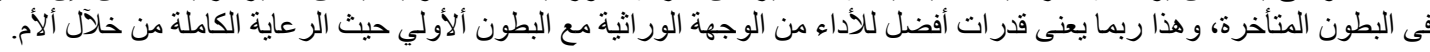


Egyptian J. Anim. Prod., 52, Suppl. Issue, April (2015):127-135 